\title{
Gender Based Differences: An Overview of Mental Health
}

\author{
Dr. Suhina Chatterjee ${ }^{1 *}$
}

\section{ABSTRACT}

The study was aimed to investigation the effect of mental health on male and female students. Mental Health Inventory was administered on 50 early adolescents (25 male and 25 female) from different schools of Ranchi. These two groups were further divided according to their socioeconomic status. Data was analyzed using mean, standard deviation and ' $t$ ' value. The findings revealed that there was significant difference between male and female students on their mental health level. Male students are more mentally healthy than female students (' $\mathrm{t}$ '=7.48., $\mathrm{P}<.01$ ). Result further revealed that socio-economic status has no significant effect on mental health.

Keywords: Mental health, Gender, Socio-economic status.

Mental health as a state of prosperity in which everyone sees himself as an able and talented person and they can cope with the normal stress of their life. Mental health describes our social, emotional, and psychological states, all wrapped up into one. Someone who experiences "good" mental health, therefore, has found a balance in his or her social, emotional and psychological areas of life.

According to Negi (2010) mental health is balance between all aspects of life- social, physical and spiritual aspect of a person. It imparts on how we manage our surroundings and make choices in our lives clearly it is an integral part of our overall health.

The WHO constitution states: "Health is a state of complete physical, mental and social wellbeing and not merely the absence of disease or infirmity." An important consequence of this definition is that mental health is described as more than the absence of mental disorders or disabilities. Bhatia (1982) considers mental health as the ability to balance feelings, desires, ambitions and ideals in one's daily living. It means the ability to face and accept the realities of life.

\footnotetext{
${ }^{1}$ PhD, Ranchi University, Ranchi, Jharkhand \& India

*Responding Author

(C) 2016 I S Chatterjee; licensee IJIP. This is an Open Access Research distributed under the terms of the Creative Commons Attribution License (http://creativecommons.org/licenses/by/2.0), which permits unrestricted use, distribution, and reproduction in any Medium, provided the original work is properly cited.
} 


\section{Gender Based Differences: An Overview of Mental Health}

According to Kornhouser(1965) "Mental health is those behaviour, perception and feeling that determine a person "es overall level of personal effectiveness, success, happiness and excellence of functioning as a person.”

The aim of this work is to discuss gender differences on mental health; a gender approach to health means to distinguish biological and social factors while exploring their interactions and to be sensitive to how gender inequality affects health outcomes.

Srivstava (1987) found that mental health of female teachers is significantly lower than that of male teachers. Indian women have been gradually coming out of traditional roles and entering into the male dominated areas. In recent years the role and status of the women have been changed tremendously. Research review highlight that women are trapped in a situation where they are getting difficulty in coping strategies to deal with it effectively and get mentally strained. Brunette \& Drake (1998) reported that women experience higher rates of mental illness than men.

Socio-economic status is also related to harmful inequalities in mental health.

There are various material and psychosocial reasons why people living in disadvantaged areas experience poorer health. For example, low income can negatively impact housing standards or reduce access to medical services; low educational attainment can affect the ability to obtain information on health services and health risk prevention; and the lack of a sense of financial security or control over one's life may create chronic stress which can negatively impact on physical as well as mental wellbeing.

According to Bradley (2002) children with low socio-economic status more often manifest symptoms of mental disorders. Desjarlais et al.,(1995) shown that mental illness is more common among people with some social disadvantage.

Ustin et ,al.,(1986) found that DSM-III disorder was higher in the lowest socio-economic status category than in the highest.

We all have mental health just like we all have physical health. And just as we monitor our bodies for potential problems or pain, we should keep tabs on our mental health and try to better recognize when it needs some attention.

\section{Hypotheses}

Some hypotheses were framed for verification:-

1) Male and female students will differ significantly in their mental health level.

2) There will be significant difference between high and low socio-economic groups of students in their mental health level. 


\section{Sample:-}

Fifty government school students were selected as sample of the study. These students were taken from different government schools of Ranchi district. 25 males and 25 female students were taking as sample. These two groups were further divided according to their socio-economic status (parental education and income). The sample was selected by stratified random sampling technique.

\section{Tools:}

In order to measure and assess the level of mental health of male and female students following tools were used.

1) Personal Data questionnaire- Personal data questionnaire developed by researcher. It included the information about each student's name, age, class, sex, parental income, education, name of the school etc.

2) Mental Health Inventory- Mental health battery developed and standardized by Arun Kumar Singh \& Alpana Sengupta (2008) was used to study the mental health of the adolescents. Reliability and validity also available in this scale.

\section{Procedure:-}

Mental Health Inventory was administered on 50 students of Government schools of Ranchi district. After collection of data the response sheet was scored individually for each subject. In order to fulfill the hypotheses of the study, the score obtained were analyzed with means, SDs and 't' values.

\section{RESULT AND DISCUSSION}

Table-1, No and percentage of total students in mental health inventory

\begin{tabular}{|l|c|c|c|}
\hline \multicolumn{1}{|c|}{ Level } & Scores & No of students & Percentage \\
\hline $\begin{array}{l}\text { Excellent mental } \\
\text { health }\end{array}$ & $70-90$ & 42 & $84 \%$ \\
\hline Average mental health & $50-69$ & 8 & $16 \%$ \\
\hline Poor mental health & $0-49$ & 0 & $0 \%$ \\
\hline
\end{tabular}

It is evident from the above table that $84 \%$ students were found to have good mental health, $16 \%$ were under average and $0 \%$ students having poor mental health.

Table-2, Means, SDs and t values of male and female school students on mental health score.

\begin{tabular}{|c|c|c|c|c|c|c|}
\hline Gender & Number & Means & SDs & MD & 't' & P value \\
\cline { 1 - 4 } Male & 25 & 75.92 & 8.50 & \multirow{2}{*}{19.08} & 7.48 & $\mathrm{P}<.01$ \\
\cline { 1 - 5 } Female & 25 & 56.84 & 9.50 & & & \\
\hline
\end{tabular}

A glance at the table- 2 shows that male students scored higher than females yielding a value of ' $\mathrm{t}$ ' ratio $7.48(\mathrm{P}<.01)$. Thus it can be said that male group is more mentally healthy than female group of students. The reason may be linked with environmental and cultural factors. Females are expected to be good in both household world and studies. They are hardly allowed to show 
their emotional burst, anger and rage. Therefore, emotional balance, adjustment process, tolerance level and other personality attributes are under great threat, which affect negatively the mental health. The present finding is supported by the earlier studies conducted by Takahiro et.al, (2012).

Table-3, Means, SDs and t values of high and low socio-economic group of school students on mental health score.

\begin{tabular}{|c|c|c|c|c|c|c|}
\hline Group & Number & Means & SDs & MD & 't' & P value \\
\cline { 1 - 6 } HSES & 20 & 78.9 & 8.50 & 4.4 & 1.94 & NS \\
\hline LSES & 20 & 74.5 & 7.78 & & & \\
\hline
\end{tabular}

The findings shown in table-3 that high socio-economic group of students have more mentally healthy (Mean= 78.9) than low socio-economic group of students (Mean= 74.5) but this difference is not statistically significant (' $\mathrm{t}$ '=1.94).

\section{MAIN FINDINGS}

The main findings of the study were:-

1) Majority of the students have good mental health (84\%).

2) Males were found to be more mentally healthy than females.

3) High \& low socio-economic groups were not differing significantly on their mental health score.

\section{REFERENCES}

Bhatia. M.,(1982).Personal Development and Mental Health. 36, 1, 215-217 .

Bradley. R.H, \& Corwyn.R.F.,(2002). Socio-economic status and child development. Annual Review of Psychology.53. 371-399.

Brunette. M., and Drake. R.E., (1998). Gender differences in homeless persons with schizophrenia and substance abuse. Community Mental Health Journal. Vol 54.627-642.

Desjarlais. R., Kleinman. A., Eisenberg, L., \& Good.B.,(1995). The role of social inequality for adolescents health. 67.709-718.

Kornhauser, A. W., (1965). Mental Health of the Industrial Worker. New York: Wiley. Ed 2nd. 44.765-770.

Negi, Y., (2010).Personality correlation of mental health, 5th ed. New York. 2(1).34-37.

Srivastava. S., (1987). Mental illness in Indian women. Economic and Political weekly. 30(45). 2879-86.

Takahiro.H., Fatima. A., Caittin.M. C.,(2012). Parental involvement and mental well-being of Indian Adolescents. 49. 915-918.

Ustin. T.B \& Sartoriu. N., (1995). Mental illness in general health care. An international study. 54.405-409. 